\title{
A rice calcium-dependent protein kinase is expressed in cortical root cells during the presymbiotic phase of the arbuscular mycorrhizal symbiosis
}

Lidia Campos-Soriano¹, Jorge Gómez-Ariza², Paola Bonfante² and Blanca San Segundo ${ }^{1 *}$

\begin{abstract}
Background: The arbuscular mycorrhizal (AM) symbiosis consists of a mutualistic relationship between soil fungi and roots of most plant species. This association provides the arbuscular mycorrhizal fungus with sugars while the fungus improves the uptake of water and mineral nutrients in the host plant. Then, the establishment of the arbuscular mycorrhizal (AM) symbiosis requires the fine tuning of host gene expression for recognition and accommodation of the fungal symbiont. In plants, calcium plays a key role as second messenger during developmental processes and responses to environmental stimuli. Even though calcium transients are known to occur in host cells during the AM symbiosis, the decoding of the calcium signal and the molecular events downstream are only poorly understood.

Results: The expression of seventeen Calcium-dependent Protein Kinase (CPK) genes representative of the four distinct phylogenetic groups of rice CPKs was monitored during the presymbiotic phase of the AM symbiosis. Among them, OsCPK18 and OsCPK4, were found to be transcriptionally activated in response to inoculation with the AM fungus Glomus intraradices. OsCPK18 and OsCPK4 gene expression was also up-regulated by fungalproduced diffusible molecules. Laser microdissection revealed expression of OsCPK18 in cortical cells, and not in epidermal cells of $G$. intraradices-inoculated rice roots, suggesting a preferential role of this gene in the root cortex. Moreover, a plasma membrane localization of OsCPK18 was observed by transient expression assays of green fluorescent protein-tagged OsCPK18 in onion epidermal cells. We also show that the myristoylation site of the OsCPK18 N-terminus is required for plasma membrane targeting.

Conclusion: The rapid activation of OSCPK18 expression in response to AM inoculation, its expression being also induced by fungal-secreted signals, together with the observed plasma membrane localization of OsCPK18, points to a role for OsCPK18 in perception of the AM fungus. The OsCPK18 gene might be considered as a marker for the presymbiotic phase of the symbiotic process. These findings provide a better understanding of the signaling mechanisms operating during the AM symbiosis and will greatly facilitate their molecular dissection.
\end{abstract}

\footnotetext{
* Correspondence: blanca.sansegundo@cragenomica.es

${ }^{1}$ Centre for Research in Agricultural Genomics (CRAG) CSIC-IRTA-UAB.

Department of Molecular Genetics. Campus UAB, Edifici CRAG, Bellaterra

(Cerdanyola del Vallès) 08193 Barcelona, Spain

Full list of author information is available at the end of the article
} 


\section{Background}

Most vascular flowering plants have the ability to establish symbiotic associations with arbuscular mycorrhizal (AM) fungi [1]. The main benefit for the plant is improved uptake of water and mineral nutrients from the soil, particularly phosphate, in exchange for photosynthetically fixed carbon [2]. The mycorrhizal symbiosis has been also associated with increased resistance to pathogen infection and tolerance to abiotic stress in several plant species [3]. As a consequence, the AM symbiosis is of tremendous significance in agricultural ecosystems.

The legumes Medicago truncatula and Lotus japonicus have been widely adopted as the reference species for studies of the AM symbiosis. Contrary to this, Arabidopsis thaliana, the model system for functional genomics in plants, has no mycorrhization ability. Rice, a monocotyledonous plant with a completely sequenced genome, establishes symbiotic associations with mycorrhizal fungi $[4,5]$. As compared to the model legume species, the genes responsible for the AM symbiotic interaction in rice are less characterized.

Successful symbiosis with AM fungi relies on the fine tuning and appropriate control of host gene expression and physiological responses. A molecular dialogue is early established between the host plant and the AM fungus and prepares the two partners for the subsequent root colonization. Signal exchange and communication starts prior to the initial cell-to-cell contact between the symbionts. Thus, plant roots exude strigolactones which have an stimulatory effect on AM growth [6]. Fungal hyphae, in turn, produce diffusible molecules, the "Myc factors" (analogous to the rhizobial Nod factors). Very recently, it was reported that the AM fungus secretes lipochitooligosaccharides which stimulate formation of AM symbiosis in diverse plant species [7]. Perception of Myc factors by the host cells triggers a rapid and transient elevation of intracellular calcium, alterations in the cellular architecture and transcriptional reprogramming of the root [8-12]. Even though both cytoplasmic [10] and nuclear [9] pre-infection $\mathrm{Ca}^{2+}$ spiking responses are elicited in M. truncatula roots in response to AM fungi, the mechanisms by which $\mathrm{Ca}^{2+}$ alterations are sensed and transduced into early AMinduced signaling remain unknown.

Once contact between the symbionts is established, the fungus enters into the root through the epidermal cells, and penetrates into the cortex where it forms highly branched structures, called arbuscules, in the cortical cells of the root. The arbuscules are the site of the major nutrient exchange between the two symbionts $[2,13,14]$.

It is also known that the plant response to Myc factors is mediated by a partially characterized signaling pathway which is required for the establishment of both rhizobial and AM symbioses, the so called common symbiosis (SYM) pathway [2,13-15]. Forward genetic analysis in the model legumes Medicago truncatula and Lotus japonicus has led to the identification of components of the SYM signaling pathway. They are: a leucine-rich-repeat receptor-like kinase, the SYMRK protein in L. japonicus (known as DMI2 for "Does Not Make Infections 2" in M. truncatula), two nucleoporins (NUP85 and NUP133), two cation channel proteins (the L. japonicus CASTOR and POLLUX proteins; DMI1a and DMIIb in M. truncatula), a calcium and calmodulin-dependent protein kinase (CCaMK in L. japonicus; DMI3 in M. truncatula) and CYCLOPS (LjCYCLOPS; DIM3-interacting protein in M. truncatula) [16-21]. CCaMK interacts with, and phosphorylates, CYCLOPS in the nucleus $[21,22]$. In rice, the function of several SYM genes appears to be conserved, including CASTOR and POLLUX (acting upstream of the calcium-spiking signal) and CCaMK and CYCLOPS (acting downstream of the calcium-spiking signal) [23-25]. Evidence also support the existence of alternative, SYM-independent signaling pathways controlling the early responses to AM fungi in both rice and M. truncatula $[25,26]$.

Transcript profiling of mycorrhizal roots allowed the identification of AM-regulated genes in several plant species, including rice [3,27-30]. However, the majority of these studies focused on the mature phase of the symbiotic process, a period in which the host root is already colonized and arbuscules are developed in the root cortical cells. Along with this, alterations in the expression of genes connected to nutrient acquisition processes, such as phosphate transporter genes, are well documented in different AM associations [31,32]. Genes involved in cellular modifications, transcriptional control and defense-related responses are also known to be regulated during the AM symbiosis [4,31].

Even though alterations in $\mathrm{Ca}^{2+}$ levels are known to occur in host cells during the presymbiotic phase, the decoding of the calcium signal is only poorly understood. On the other hand, it is well established that Calcium-dependent protein kinases (CPKs or CDPKs) are important $\mathrm{Ca}^{2+}$ sensors in signaling processes during growth, development and stress responses in plants $[33,34]$. CPKs belong to the CDPK/SnRK superfamily of protein kinases and represent a differentiated group of protein kinases found in plants, algae and protists [34-36]. They possess a characteristic structure consisting of four domains: an amino terminal variable domain, a serine/threonine kinase domain, a junction autoinhibitory domain, and a C-terminal calmodulin domain. These features make CPKs ideally structured to rapidly perceive alterations in intracellular calcium concentration and translating them into protein phosphorylation 
cascades. CPK functioning is, however, different from that of CCaMK functioning, since CPKs do not require calmodulin for their activation. $\mathrm{Ca}^{2+}$ binds directly the calmodulin domain of CPKs and induces a conformational change resulting in kinase activation [34]. The available information on plant CPKs from various plant species indicates that they are encoded by multigene families and that whereas some of the genes are ubiquitously expressed, others show a tissue-specific pattern of expression or are regulated by stress (wounding, salinity, cold, drought, pathogen infection) $[33,37,38]$.

Knowing that $\mathrm{Ca}^{2+}$ plays a central role in the AMinduced signaling pathway, it was of interest to investigate to what extent CPKs are involved in the AM-induced signaling pathway. Towards this goal, the expression pattern of seventeen $c p k$ genes was monitored in rice plants that have been inoculated with the AM fungus Glomus intraradices. We provide evidence that the expression of two distinct $c p k$ genes, the OsCPK18 and OsCPK4 genes, is rapidly induced during the presymbiotic phase of the rice/G. intraradices interaction. OsCPK18 and OsCPK4 gene expression is also activated by fungal-produced diffusible fungal signal(s). By using the laser microdissection (LMD) technology, OsCPK18 expression was detected in cortical cells, but not epidermal cells, of the G. intraradices-inoculated rice roots. Moreover, a plasma membrane localization of OsCPK18 is here reported, the myristoylation site of OsCPK18 being required for its plasma membrane localization. Together, these findings support that OsCPK18 might play a role during recognition of the AM fungus by the host cells.

\section{Results}

Expression of CPK genes in AM-inoculated rice roots

A genome-wide analysis of rice $C P K$ genes identified 31 genes which are distributed into four phylogenetic groups (I-IV) [39,40]. Moreover, a comparison of the rice $C P K$ genes distinguished 11 closely related pairs which, most probably, have arisen via sequential duplication events, the OsCPK1/15, OsCPK2/14, OsCPK3/16, OsCPK4/18, OsCPK5/13, OsCPK7/23, OsCPK8/20, OsCPK11/17, OsCPK21/22, OsCPK24/28 and OsCPK25/ 26 pairs [40]. Based of the homology and phylogenetic relatedness among the rice $C P K$ genes, we selected a subset of seventeen $C P K$ genes representative of the four distinct phylogenetic groups of rice CPKs in which at least one representative member for each pair of closely related $C P K$ genes was present. The subset of genes assayed in this work included OsCPK7, OsCPK10, OsCPK13, OsCPK17 and OsCPK24 from Group I; OsCPK2, OsCPK15, OsCPK19 and OsCPK25 from Group II; OsCPK8, OsCPK9, OsCPK16 and OsCPK22 from Group III; and OsCPK4, OsCPK18, OsCPK30 and OsCPK31 from Group IV.
The expression pattern of selected rice $C P K$ genes and their transcriptional response to inoculation with the AM fungus G. intraradices, were examined during the presymbiotic phase of the symbiotic process. A preliminary screening was carried out by semiquantitative RT-PCR experiments with RNA samples obtained from whole rice roots that had been inoculated with fungal spores using the single sandwich method. Total RNA was isolated at 24, 48, 72 and 96 hours after inoculation of the rice roots with G. intraradices, as well as from mock-inoculated rice roots. Many $C P K$ genes were found to be expressed in rice roots and at different levels (Additional file 1: Figure S1). Among them, the OsCPK4 and OsCPK18 genes were expressed at the highest levels. Moderate to low levels of expression were observed for OsCPK10, OsCPK13, OsCPK17, OsCPK24, OsCPK15, OsCPK19, OsCPK8 and OsCPK9, whereas OsCPK30 transcripts were barely detected (Additional file 1: Figure S1). The $O s C P K 7$ and $O s C P K 16$ genes showed expression profiles similar to those shown for OsCPK8 and OsCPK30, respectively (results not shown). Taken in the whole, the expression level of the various $C P K$ genes here investigated appears not to be dramatically affected upon inoculation with G. intraradices, with the exception of OsCPK4 and OsCPK18 expression (Additional file 1: Figure S1)

For a comparison, the expression of the known $S Y M$ genes from rice, namely the OSSYMRK, OsPOLLUX, OsCASTOR and OsCCaMK genes, was also examined. This analysis revealed up-regulation of OSSYMRK, OsPOLLUX and OsCCaMK in response to G. intraradices at 72 and 96 hours post-inoculation (Additional file 1: Figure S1). The observed induction of these genes indicates that the host plant cells perceive and respond to the AM fungus through the activation of the AMspecific SYM signaling pathway.

Since RT-PCR analyses do not provide reliable quantitative data of gene expression, quantitative reverse transcription-PCR (RT-qPCR) was used to further characterize the effect of G. intraradices inoculation on OsCPK4 and OsCPK18 gene expression. By using the single sandwich system for fungal inoculation, up-regulation of OsCPK18 gene expression occurred as early as $24 \mathrm{~h}$ post-inoculation with G. intraradices (Figure 1A, upper panel). The level of OsCPK18 transcripts remained higher at the subsequent time points in the G. intraradices-inoculated roots compared to mock-inoculated roots. Concerning OsCPK4, its expression was also found to be up-regulated in response to G. intraradices inoculation during the time period of 24-72 hours. OsCPK4 expression returned to a level similar to that of non-inoculated roots by $96 \mathrm{~h}$ post-inoculation (Figure 1A, middle panel). Finally, OsCCaMK expression increased in G. intraradices-infected roots relative to mock-inoculated roots by 72-96 hours post-inoculation (Figure 1A, lower panel). 


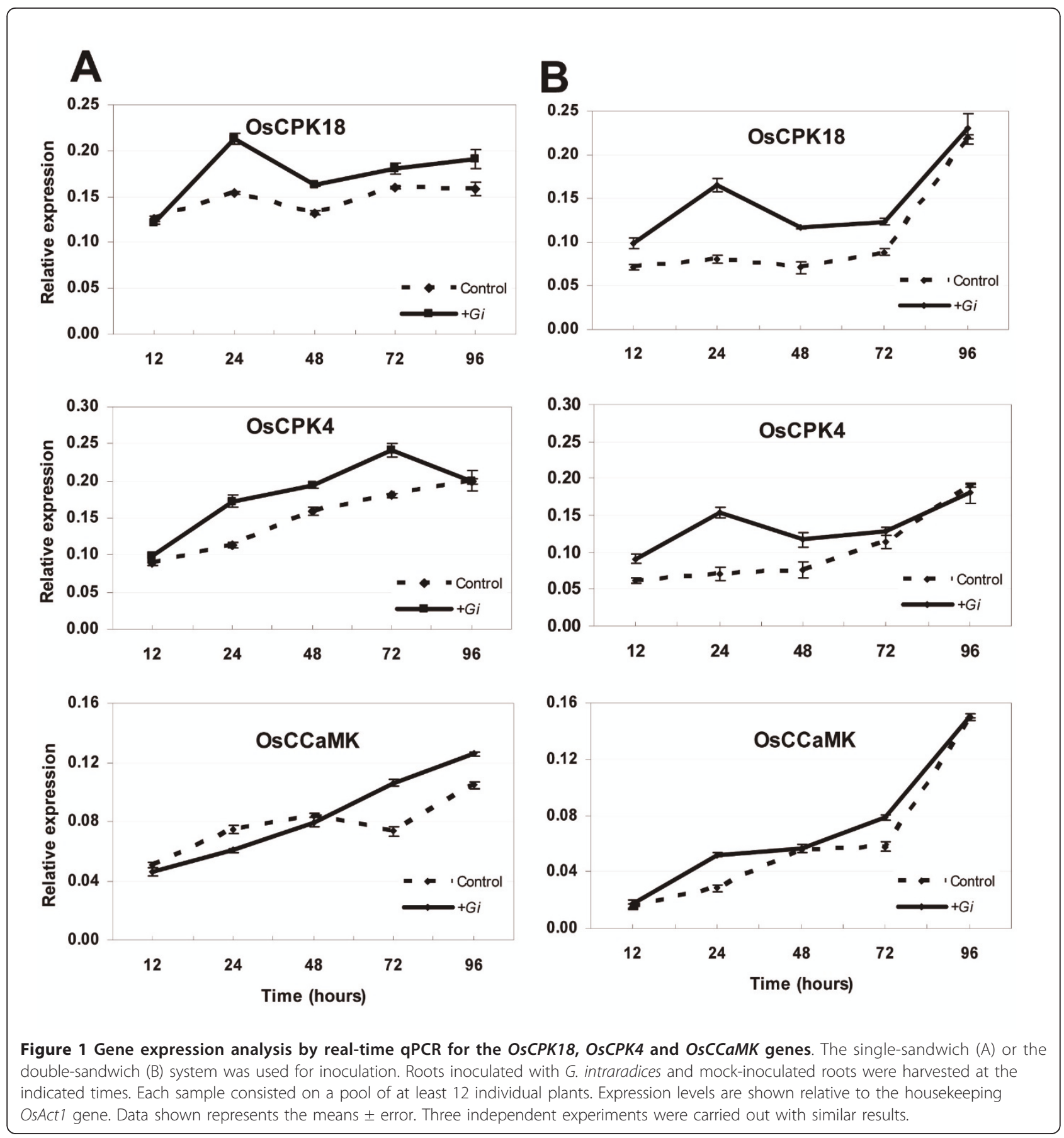

Overall, gene expression studies revealed up-regulation of the rice OsCPK4 and OsCPK18 genes during the presymbiotic phase of the AM symbiosis. These results were consistently observed in all three independent experiments. Although the expression of the OsCPK18, OsCPK4 and OsCCaMK genes was up-regulated in AM-inoculated roots compared to non-inoculated roots, it is also true that the amplitude of the differential expression for these genes was not very high during the time period here analyzed. Concerning OsCCaMK for which a role during AM symbiosis has been demonstrated in rice [23], its variation in the expression level in response to AM inoculation is also low and appears to occur at a later time point compared to the observed activation of OsCPK18 and OsCPK4 gene expression. 


\section{Diffusible factors released by $G$. intraradices induce OsCPK18 and OsCPK4 expression in rice roots}

It is generally assumed that plants perceive AM fungi even before physical contact between the two symbionts, and that recognition of Myc factors triggers alterations in $\mathrm{Ca}^{2+}$ levels and transcriptional responses in host roots $[7,9,11,41]$. In this work, the double sandwich method was used to investigate whether the observed induction of OsCPK18 and OsCPK4 expression is attributable to diffusible factors released by the fungus. This system prevents contact between the two symbionts while allowing the exchange of signal molecules [42]. OsCPK18 and OsCPK4 expression was analyzed by RTqPCR (Figure 1B). When using the double sandwich system for inoculation of rice roots, OsCPK18 and OsCPK4 expression was found to be rapidly activated in response to G. intraradices inoculation (Figure 1B, upper and medium panel). However, induction of OsCPK4 and OsCPK18 expression was not maintained with time (the maximum induction occurred at $24 \mathrm{~h}$ post-inoculation for the two genes). Similar levels of transcript accumulation were observed in G. intraradices- and mock-inoculated roots at the latest time point here analyzed (96 hours post-inoculation). From these results it can be concluded that a diffusible fungal factor elicits expression of the rice OsCPK18 and OsCPK4 genes, and that this activation is transient. Most probably, contact between the two partners is needed to maintain the expression of these genes in an activated manner at the subsequent stages of the infection process. Under the same experimental conditions, an activation of OsCCaMK gene expression also occurred at $24 \mathrm{~h}$ postinoculation although differences in OsCCaMK gene expression between AM-inoculated and mock inoculated roots were lower than those observed for the $C P K$ genes (Figure 1B, lower panel).

\section{OsCPK18 expression in microdissected root cells}

The laser-microdissection (LMD) technology has been successfully used for gene expression analysis in arbuscule-containing cells in different plant species such as Medicago, Lotus or tomato [27-29,43,44]. A variety of protocols have been developed for LMD of root tissues in order to identify the most appropriate fixation and embedding conditions that preserve cellular morphology, while still enabling extraction of high quality RNA for PCR amplification. In this way, laser microdissected cells can be used for RNA extraction and expression studies, thus avoiding the dilution effect of RNA samples extracted from whole roots. In this work, the protocol previously developed [43] for the isolation of cells from tomato roots was applied for the acquisition of rice root cells. The use of paraffin tissue preparations coupled to Methacarn fixation provided rice root tissues that satisfactorily retain the cellular morphology. Next, RNA samples of high quality were obtained from laser microdissected root cells.

Sections of the epidermis and the cortex were prepared from G. intraradices- and mock-inoculated rice roots at four days after inoculation (Figure 2). Cells, either epidermal or cortical cells, were collected pooled and used for RNA extraction. The cell type-specific pattern of expression of the OsCPK18 gene was examined in laser microdissected cells. As it is shown in Figure 2F, OsCPK18 transcripts were exclusively detected in cortical cells of G. intraradices-inoculated rice roots. OsCPK18 transcripts were not detectable in epidermal cells of the fungal-inoculated roots. The absence of PCR amplification products in epidermal cells of the fungal-inoculated roots was confirmed by nested PCR (results not shown). Transcripts for the ubiquitin1 gene (Figure 2F) or the cyclophilin gene (results not shown) were also detected

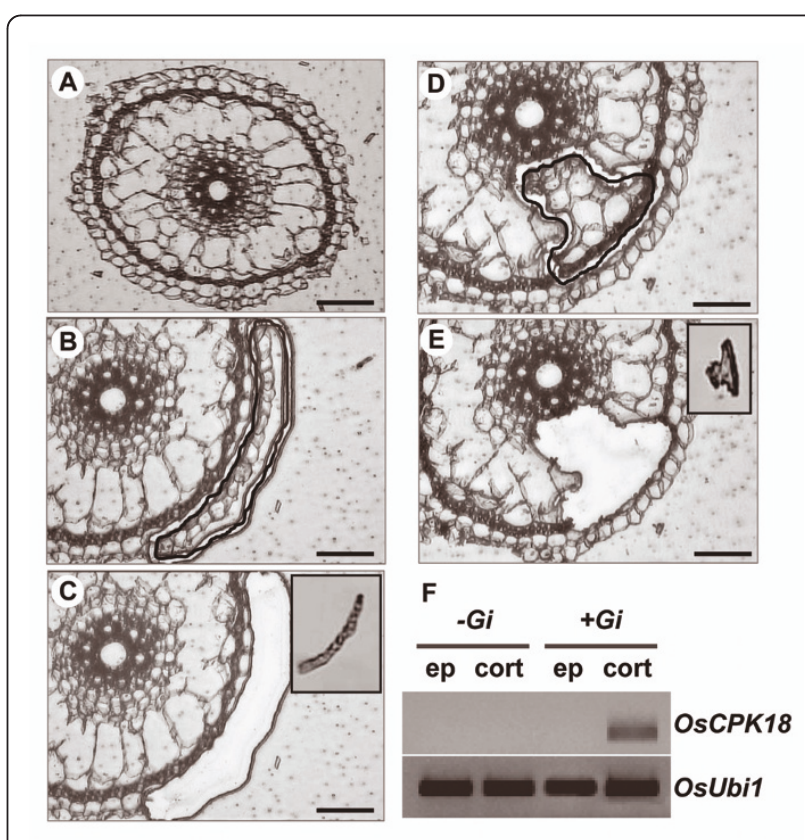

Figure $\mathbf{2}$ Laser microdissection of epidermal and cortical cells from rice roots. (A) Typical transverse section from the rice root. ( $B$ and $C$ ) Representative transverse sections with targeted epidermal cells before (B) and after (C) cutting with the laser microdissector. ( $D$ and $E$ ) Representative transverse sections with targeted cortical cells before (D) and after (E) cutting with the laser microdissector. Insets in C and E show captured microdissected cells. Two independent experiments were carried out for isolation of epidermal and cortical rice root cells by LMD. (F) RT-PCR analysis to detect OsCPK18 transcripts in laser microdissected cells from rice roots. Cells were harvested from $G$. intraradices-inoculated $(+G i)$ and mock-inoculated (-Gi) roots. Total RNA samples were obtained from pooled microdissected cells. Expression analysis was carried out using the one-step procedure for RT and PCR amplification. OsCPK18 transcripts were detected only in cortical cells. Bars, $100 \mu \mathrm{m}(\mathrm{A})$, $50 \mu \mathrm{m}$ (B to E). 
in all the RNA samples obtained from laser microdissected cells. The use of gene-specific primers that span introns excluded the possibility of genomic DNA in total RNA samples used for RT-PCR analyses. The absence of an amplified product in $\mathrm{RT}$-negative reactions also excluded any DNA contamination in RNA samples obtained from laser microdissected cells (results not shown). Finally, OsCPK4 transcripts were detected in RNA samples obtained from the two cell types captured from fungal-inoculated and control roots, this observation further supporting the integrity of the RNA samples used in this study (Additional file 2: Figure S2).

When comparing the results obtained on OsCPK18 expression in laser microdissected cells (Figure 2F) and whole roots (Figure 1), an apparent contradiction is observed. Thus, OsCPK18 transcripts were not detected in isolated cells from mock-inoculated roots (Figure 2F) whereas RT-qPCR analysis revealed OsCPK18 expression in whole roots (Figure 1A, upper panel). This finding could be explained taking into account the plant material and experimental approach used in these studies. In this work, only two cell types of the root were harvested for LMD-related analyses (epidermal and cortical cells). Thus, the detection of OsCPK18 expression in whole mockinoculated roots could be due to the presence of cell types constitutively expressing OsCPK18 that were not analyzed with LMD (i.e. cells from the central cylinder). Additionally, transversal sections were routinely made at aprox. 2 $\mathrm{cm}$ from the root tip. Thus the observed expression of the OsCPK18 gene in regions of the rice root other than that used for laser microdissection (i.e. meristems) might well account for the observed OsCPK18 expression in mockinoculated whole roots. This observation also illustrates the fact that results obtained in gene expression by using entire roots might often be misinterpreted and spatial differences in gene expression might not be perceived by using whole roots. Clearly, a more detailed analysis of OsCPK18 expression during growth and development of the rice root is needed.

\section{Subcellular localization of OsCPK18}

Onion epidermal cells are widely used as a convenient system in which to evaluate the subcellular location of GFPtagged proteins. Accordingly, the subcellular localization of OsCPK18 was investigated in onion epidermal cells transiently expressing gene fusions to the green fluorescent protein (GFP) (Figure 3A). Confocal microscopy of transformed onion cells revealed that OsCPK18-GFP localizes to the cell periphery, likely the plasma membrane (Figure 3B). As expected, onion cells expressing the GFP gene showed fluorescence distributed throughout the cell (Figure 3C).

Onion epidermal cells are also particularly useful for analysis of plasma membrane proteins because the

\section{A

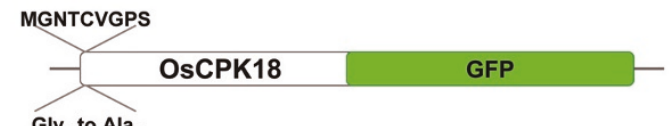 \\ $\mathrm{Gly}_{2}$ to $\mathrm{Ala}_{2}$}

B
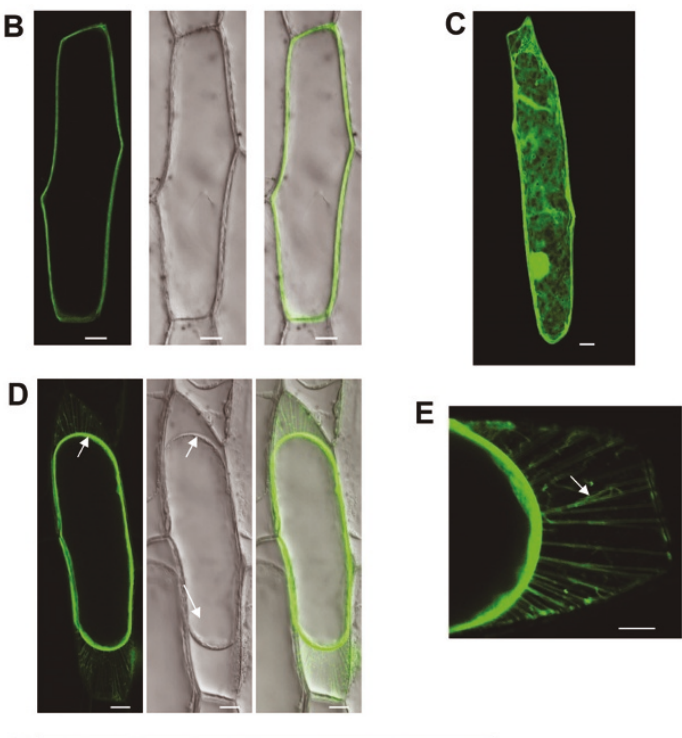

$\mathbf{F}$

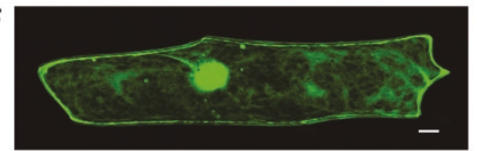

Figure 3 Plasma membrane localization of OsCPK18. Wild-type OsCPK18 and a N-terminal myristoylation mutant were transiently expressed as GFP fusion proteins in onion epidermal cells. Confocal images were taken $24 \mathrm{~h}$ post-bombardment. (A) Diagrams of the constructs used for particle bombardment of onion epidermal cells, wild OsCPK18-GFP and the mutant OsCPK18-GFP fusion protein in which the Gly $y_{2}$ was mutated to Ala $\left(\mathrm{Os} C \mathrm{PK} 18_{\mathrm{G} 2 \mathrm{~A}}\right)$. (B) Localization of wild OsCPK18-GFP fusion protein. Merged pictures of the green fluorescence channel with the corresponding light micrographs are shown in on the right. (C) Localization of GFP. (D) Onion cells after plasmolysis with mannitol (15 min of treatment). Light micrographs show the shrinkage of the protoplast (white arrow). (E) Treatment with mannitol renders the Hechtian strands (arrows) attaching the plasma membrane to the cell wall. (F) Onion epidermal cells expressing a mutated version of OsCPK18 with an altered myristoylation site (OsCPK18 $8_{\text {G2A }}$-GFP). While the wild-type protein is localized to the plasma membrane, the $G_{2} A$ mutant protein lost its specific plasma membrane localization. Projection $(B, C, D, F)$ and individual (E) sections are shown. Scale bars $=20 \mu \mathrm{m}(B, C, D, F)$, $10 \mu \mathrm{m}(\mathrm{E})$.

environmental conditions can be manipulated to cause plasmolysis and partial separation of the plasma membrane from the cell wall. The onion epidermal cells were plasmolyzed after being transformed with OsCPK18GFP. In plasmolyzed onion cells, the OsCPK18-GFP displayed a pattern consistent with its location in the plasma membrane of the shrunken protoplasm (Figure 3D). Under these conditions, protoplast pull 
away from the cell wall, leaving large numbers of thin plasma membrane bridges, known as Hechtian strands, firmly anchored to the cell wall (Figure 3E).

Analysis of the amino acid sequence of OsCPK18 shows that the OsCPK18 polypeptide possess a N-terminal myristoylation site at the Gly residue at position $2\left(\mathrm{Gly}_{2}\right)$ suggestive of N-myristoylation. The need for this lipid modification to promote and stabilize membrane association of certain CPKs has been experimentally demonstrated [37]. To address the role of the myristoylation site of OsCPK18 in plasma membrane association, a mutation at the N-terminal myristoylation site (MGNTCVGPS) of the OsCPK18 polypeptide was made. The Gly2 was converted to Ala (G2A, referred to as OsCPK18 $\left.{ }_{\mathrm{G} 2 \mathrm{~A}}\right)$ and fused to GFP (Figure 3A). Transient expression in epidermal onion cells showed that the Gly 2 mutation abolished the plasma membrane localization of OsCPK18 (Figure 3F). Instead, a distribution throughout the cell was observed for the mutated version of OsCPK18 similar to that of the GFP alone. These findings suggest that the $\mathrm{N}$-terminal myristoylation site is required for subcellular localization of OsCPK18 at the plasma membrane.

\section{Phylogenetic analysis of cpk genes}

In this work, the evolutionary relationships among CPKs from rice and known CPKs from other plant species establishing association with AM fungi was determined. For this analysis, the full-length CPK protein sequences from cereal species, namely wheat and maize, as well as CPKs so far characterized in the model symbiotic species of Medicago were used. As previously mentioned, the rice genome contains 31 CPK genes which classify into four major phylogenetic groups (I-IV) $[39,40]$. Known CCaMK protein sequences from rice, wheat and Medicago were also considered. In this respect, the rice genome contains a single CCaMK gene [39]. As Arabidopsis is not a host for AM fungi, this species was not included in the phylogenetic analysis.

Phylogenetic trees of CPK and CCaMK proteins were constructed based on the neighbor-joining method (Figure 4) or the maximum parsimony method (Additional file 3: Figure S3). The aligment of the various proteins used for construction of the phylogenetic tree is presented in Additional file 4). Similar to what was previously reported [40], the rice CPKs clustered into four distinct phylogenetic groups (Figure 4). Four distinct CPKs, OsCPK18, OsCPK4, OsCPK30 and OsCPK31, cluster into an independent clade of CPKs, the Group IV, which appears to have diverged significantly from the other rice CPK sequences. Noticeably, results here presented show that OsCPK18 and OsCPK4 are both up-regulated by the AM fungus G. intraradices, these particular CPKs belonging to Group IV of rice CPKs. As for the other members of the Group IV of rice CPKs,

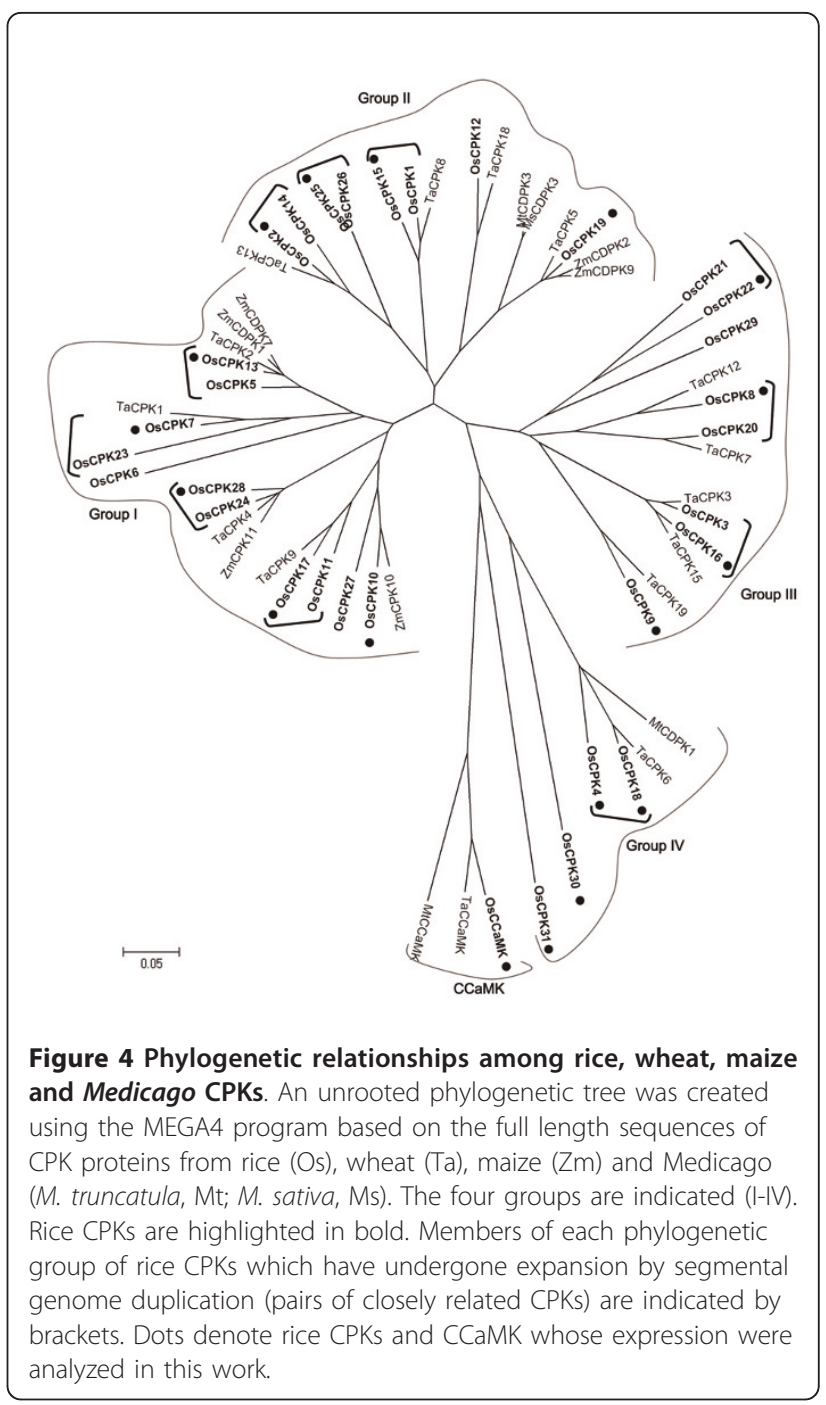

no expression could be detected in the rice roots for Oscpk31, whereas Oscpk30 exhibited a low expression but no responsiveness to $\mathrm{AM}$ inoculation.

Some interesting observations came from the phylogenetic analysis of CPK and CCaMK proteins. Firstly, OsCPK18 and OsCPK4 appear to be closely related to the AM-associated MtCDPK1 (Figure 4). Secondly, Group IV of rice CPKs and CCaMKs are closely related each other. Indeed, Group IV of rice CPKs appears to be more related to CCaMKs than to the other rice CPKs. Here, it is worthwhile to mention that the essential function of $M t C C a M K$ and OsCCaMK during the mycorrhizal symbiotic association is well documented $[18,23]$. Finally, the OsCPK18 is clearly related to TaCPK6, one of the 20 CPKs described in wheat [45].

Sequence analysis of the OsCPK18 and OsCPK4 promoters Knowing that the OsCPK18 and OsCPK4 genes are transcriptionally activated in response to inoculation with 
the AM fungus G. intraradices, it was of interest to investigate whether symbiosis-related cis-elements are present in the promoter region of these genes. The OsCPK18 and OsCPK4 promoter analysis was carried out using the PLACE algorithm [46] and extended to genes that are known to be required for both AM and rhizobial root nodule symbioses, such as the MtCPK1 and $M t C C a M K$ genes from M. truncatula and the OsCCaMK from rice.

Analysis of the $2 \mathrm{~kb}$ promoter region of the OsCPK18 and OsCPK4 genes revealed the presence of the CTCTT element (NODCON2GM) which is found up to five and six times in the OsCPK18 and OsCPK4 promoter, respectively (Figure 5 and Additional file 5: Tables S1 and S2). The NODCON2GM as well as the NODCON1GM element (AAAGAT) are characteristic motifs of promoters from genes that are regulated during root nodule and AM symbiosis. These motifs are also part of the "organ-specific element" (OSE) sequence [47]. The $M t C P K 1$, OsCCaMK and MtCCaMK promoters contain several copies of the NODCON1GM and NODCON2GM consensus sequences.

Interestingly, multiple copies of the ABRE-related consensus motif [(C/A)ACG(T/C)G(T/G/C), ABRERAT$\mathrm{CAL}]$ were present in the proximal region of the

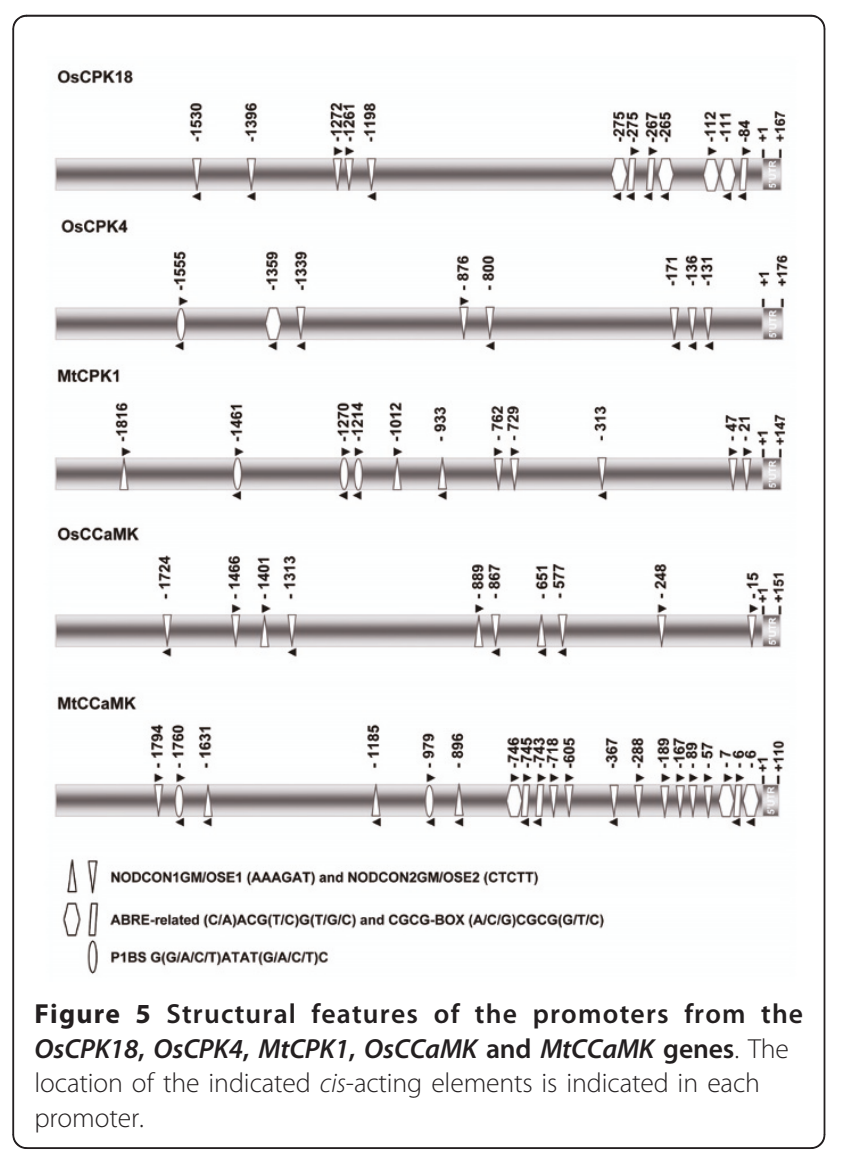

OsCPK18 promoter (Figure 5 and Additional file 5: Tables S1 and S2). The ABRE-related motif is a cis-element identified in the upstream region of $162 \mathrm{Ca}^{2+}$-responsive up-regulated genes [48]. Furthermore, up to three copies of the CGCG-BOX element (GCCGCGGC) are found in the Oscpk18 promoter, this element being involved in $\mathrm{Ca}^{++} /$calmodulin-regulated gene expression [49] (Figure 5 and Additional file 5: Tables S1 and S2). The OsCPK4 promoter region contains one copy of the ABRErelated motif element. The $\mathrm{G}(\mathrm{G} / \mathrm{A} / \mathrm{C} / \mathrm{T}) \mathrm{ATAT}(\mathrm{G} / \mathrm{A} / \mathrm{C} / \mathrm{T}) \mathrm{C}$ (P1BS element) was recognized in the OsCPK4, MtCPK1 and $M t C C a M K$ promoters (Figure 5 and Additional file 5 : Tables S1 and S2). This element is found in the upstream region of phosphate starvation responsive genes from several plant species [50].

Finally, the OsCPK18 and OsCPK4 promoters harbor multiple stress-related cis-acting elements, including elements that are known to confer responsiveness to pathogen-regulated genes. Some of them were represented many times in these promoters, such as the TGAC-containing W box of WRKY transcription factors (Additional file 5: Tables S1 and S2). In line with this, we recently reported the activation of defense-and stress-related genes during colonization of rice roots by G. intraradices [4]. Whether the expression of the OsCPK18 and OsCPK4 genes is regulated during pathogen infection in roots remains to be determined.

Overall, this study revealed the presence of symbioticrelated motifs, as well as putative elements related to $\mathrm{Ca}^{2+}$ regulation of gene expression, in the promoter region of the OsCPK18 and OsCPK4 genes. This observation is consistent with the observed induction for the two $C P K$ genes in AM-inoculated rice roots.

\section{Discussion}

In this work, the expression of $C P K$ genes was monitored during the early stages of the AM symbiosis in rice. The OsCPK18 and OsCPK4 consistently showed up-regulation in response to AM inoculation. Evidence is also presented on the transcriptional activation of OsCPK18 and OsCPK4 expression by diffusible molecules produced by $G$. intraradices. When comparing the expression profiles of the rice $C P K$ and $C C A M K$ genes, it appears that activation of the two $C P K$ genes (OsCPK18 and OsCPK4) occurs earlier than that of OsC$C a M K$ pointing to a role for these particular rice $C P K$ genes at the early stages of the symbiotic process. The observation that the OsCPK18, OsCPK4, OsCCaMK, $M t C P K 1$ and $M t C C a M K$ genes share symbiotic-related cis-elements in their promoters is also indicative of the transcriptional regulation of these genes as part of the signaling mechanisms involved in the AM symbiosis in rice. An expanded view of OsCPK18 gene expression came from expression studies in laser microdissected 
cells isolated from rice roots. At 4 days post-inoculation with G. intraradices, OsCPK18 was detected in cortical cells and not in epidermal cells.

Clearly, the specificity of a CPK functioning in a given signaling pathway may be achieved not only by a differential pattern of expression but also by targeting of the CPK protein to a particular subcellular compartment. Along with this, CPK proteins appear to be widely distributed among subcellular compartments including cytosol, peroxisome, plasma membrane, oil bodies and nucleus, as well as in association with actin filaments, mitochondria and the endoplasmic reticulum [33]. Our results in transformed onion cells clearly demonstrated that OsCPK18 localizes to the plasma membrane. Moreover, the association of OsCPK18 to the plasma membrane is possibly linked to $\mathrm{N}$ - terminal myristoylation of this protein.

Knowing that CPKs act as $\mathrm{Ca}^{2+}$ sensors in plant signaling, and that $\mathrm{Ca}^{2+}$ plays an important role in the $\mathrm{AM}$ symbiosis, a function of OsCPK18 as a $\mathrm{Ca}^{2+}$ sensor during the AM-induced host responses to AM fungi can be envisaged. Thus, perception of the fungal-produced symbiotic signal(s) would activate downstream signaling events required for the establishment of the symbiotic association, including the cytoplasmic and nuclear $\mathrm{Ca}^{2+}$ spiking responses [9-11]. Alterations in the $\mathrm{Ca}^{2+}$ level would be itself a major factor in mediating up-regulation of OsCPK18 gene expression in the nucleus, as judged by the presence of the $\mathrm{Ca}^{2+}$-responsive cis-elements in the OsCPK18 promoter region [48]. In line with this, previous studies in Arabidopsis revealed the presence of ABRE-related sequences in $\mathrm{Ca}^{2+}$-responsive genes, and exclusively in up-regulated $\mathrm{Ca}^{2+}$-responsive genes [48]. Tetramers of the ABRE-cis element are sufficient to confer this transcriptional activation in response to $\mathrm{Ca}^{2+}$ transients. The presence of multiple $\mathrm{Ca}^{2+}$-responsive cisregulatory elements in the promoter region of the OsCPK18 gene (e.g. ABRE-related and CGCG-box elements) favors the possibility of a $\mathrm{Ca}^{2+}$-mediated up-regulation of OsCPK18 gene expression. The identity of the transcription factors that respond to rapid transient $\mathrm{Ca}^{2+}$ signals and that subsequently activate gene expression through ABRE-related cis-elements remains to be determined.

In addition to its transcriptional activation, a direct regulation of the OsCPK18 enzyme activity by $\mathrm{Ca}^{2+}$ can be expected. Thus, it is well known that the activity of CPKs is regulated by the binding of calcium to its intrinsic calmodulin-like domain. At basal $\mathrm{Ca}^{2+}$ concentrations, the functional autoregulatory domain acts as a pseudosubstrate that inhibits the kinase activity of CPKs (autoinhibited structure). In response to transient increases in the level of cellular $\mathrm{Ca}^{2+}$, CPKs undergo conformational changes that activate their kinase activity (calcium-bound structure) [51]. It is then reasonable to assume that the plasma membrane-localized OsCPK18 protein sense the AM-induced increase in cytoplasmic $\mathrm{Ca}^{2+}$ levels and transduce this signal into phosphorylation processes. The OsCPK18-mediated signaling processes might then be crucial for root colonization and accommodation of the fungal symbiont in the root cortex. The identification of downstream targets of the OsCPK18 kinase activity requires, however, further investigation.

On the other hand, our phylogenetic analysis of CPKs and CCaMK of plant species that are able to establish mycorrhizal associations revealed that Group IV of CPKs and CCaMK are closely related each other pointing to an evolutionary relationship between the two families of protein kinases. In other studies carried out in the green alga it was proposed that $\mathrm{CCaMK}$ originated through gene duplication from CPK during green alga evolution [52] Altogether, these findings are in clear support a functional specialization of members of the Group IV of CPKs and their relatedness with CCaMK functioning. Adaptation steps probably occurred in different plant species that determined their functional specialization and symbiosis-specific regulation.

The current work also provides a foundation for further functional investigation of the complex CPK family in relationship to the mycorrhization ability in another cereal species, such as wheat. Thus, the phylogenetic analysis of CPKs revealed that OsCPK18 and OsCPK4 are closely related to the wheat TaCPK6 protein as well as to the Medicago MtCDPK1 protein. For MtCDPK1 a role during the establishment of the AM symbiosis is well documented [53]. It is then tempting to speculate that the TaCPK6 gene might exhibit an AM-regulated expression pattern in wheat plants.

An intriguing aspect is the presence of three Arabidopsis proteins in Group IV of CPKs [39], even though Arabidopsis is not a host for AM fungi. To this point, it has been proposed that genes required for other aspects of plant development might have been recruited to function in symbiotic pathways. In line with this, inactivation of the MtCDPK1 gene is associated to a significant reduction of rhizobial and mycorrhizal symbiosis and also results in stunted roots and short root hairs in M. truncatula [53]. In other studies, impairment of root hair development results in defective symbiotic interactions in L. japonicus [54]. Then, the Arabidopsis CPKs within Group IV of CPKs might play a role in normal processes during root growth and development. The finding of SYM genes in species that do not associate with AM fungi (e.g. Arabidopsis and Physcomitrella), also supports that specific genes functioning in normal developmental processes in roots might also regulate mycorrhizal infection. If so, this fact, would explain the 
observed expression of OsCPK18 in experiments carried out on whole roots by RT-qPCR.

\section{Conclusions}

This study provides a new view of the molecular mechanisms involved in the AM symbiosis in rice while defining an OsCPK18-mediated signaling pathway functioning during this process. The rapid activation of OsCPK18 expression in response to AM inoculation, its expression being also induced by fungal-secreted signals, together with the observed plasma membrane localization of OsCPK18, suggest that OsCPK18 might play a role in perception and/or recognition of the AM fungus in rice. Compared to legume species, less effort has been invested in the characterization of the AM symbiotic interaction in this important crop species. OsCPK18 might be considered as a marker for the presymbiotic phase of the symbiotic process that might play a preferential role in the root cortex. The identification of additional components of the AM-induced signaling processes in which OsCPK18 participates can be now approached. A major challenge for the future research is to determine whether interconnections and synergistic functions exist between CPKs and SYM components, this interplay determining recognition and compatibility between the two symbiotic partners.

\section{Methods}

\section{Plant material and growth conditions}

Rice (Oryza sativa cv Nipponbare) was used as the experimental material. Seeds were surface sterilized with $70 \%$ ethanol for $1 \mathrm{~min}$, sodium hypochlorite $(30 \% \mathrm{v} / \mathrm{v})$ for $30 \mathrm{~min}$, and extensively washed with sterile water (four times, $10 \mathrm{~min}$ each). Seeds were germinated in agar $(0,4 \%)$ prepared with minimal medium. Seedlings

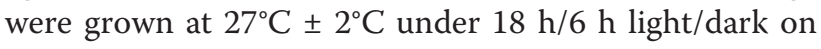
vertical plates.

G. intraradices (DAOM197198) spores were prepared from monoxenic cultures of carrot roots that were grown for three months as previously described [4]. Roots and G. intraradices cultures were axenically solubilized in 5 volumes of sterile $10 \mathrm{mM}$ sodium-citrate, $\mathrm{pH} 6.0$ for $15 \mathrm{~min}$, at $37^{\circ} \mathrm{C}$ and filtrated four times through a $250 \mu \mathrm{M}$ sieve. Rice roots were inoculated with the G. intraradices spore suspension using either the single sandwich [29] or the double sandwich [42] system.

For the single sandwich method, the rice seedlings were directly inoculated with the arbuscular mycorrhizal spore suspension, or mock-inoculated (sterile water), and placed between two sterile nitrocellulose membranes (Millipore, pore diameter $0.45 \mu \mathrm{m}$ ). For the double sandwich method, the rice seedlings were first placed between two Millipore membranes. The membrane-covered seedlings were then inoculated with the fungal spore suspension and covered with a second layer of membranes. In this way, the physical contact between the fungus and the root is avoided. The assembled sandwich containing the inoculated seedlings was placed in Petri dishes containing 0.4\% agar in minimal medium. Since Millipore membranes are permeable to diffusible molecules, the root cells can perceive fungal signals in the double sandwich method even thought physical contact between the two symbionts does not occur. Control seedlings were inoculated with sterile water.

\section{Tissue preparation and laser microdissection}

The method previously described [43] was adapted for the isolation of cells from G. intraradices-inoculated and mock-inoculated rice roots. Root pieces of $4-8 \mathrm{~mm}$ in length were dissected with a razor blade and immediately transferred into freshly prepared Methacarn solution (absolute methanol/chloroform/glacial acetic acid 6:3:1). Roots were maintained in the fixative solution overnight at $4^{\circ} \mathrm{C}$, and subsequently dehydrated in a graded series of ethanol at $4{ }^{\circ} \mathrm{C}: 50,70$ and $90 \%$ in sterile water and $100 \%$ ethanol, followed by isopropanol (twice), with each step on ice for $1 \mathrm{~h}$. The isopropanol was replaced gradually with paraffin (Paraplast Plus; Sigma Aldrich, St. Louis). Transverse root sections of 10-15 $\mu \mathrm{m}$ were made using a Reichert Jung 2050 SuperCut Motorized Microtome (Leica, Arnsberg, Germany). Ribbons were arranged on RNase-free, UV-treated, PEN-membrane $2.0 \mu \mathrm{m}$ slides. Slides were kept in a slide warmer at $40^{\circ} \mathrm{C}$ until dry and stored at $4{ }^{\circ} \mathrm{C}$ and used within two days.

The Leica LDM6000 Laser Microdissection system (Leica, Bannockburn, IL, USA) was used for laser microdissection (LMD). Just before use, the paraffin sections were deparaffinised in a neoclear (Merck, Darmstadt, Germany) treatment for 10 min followed by $100 \%$ ethanol for $2 \mathrm{~min}$, and then air dried. The deparaffinised slides were placed face down on the microscope. The tissues were visualized on a computer monitor through a video camera. Epidermal and cortical cells were marked and then cut using a UV laser (337-nm wavelength). Target cells were collected without any extra forces into the cap of a microcentrifuge (RNase-free PCR tube caps). For each cell type, we isolated at least 1500 cell sections per biological replicate, and two independent biological replicates were made. After collection, $50 \mu \mathrm{l}$ of RNA extraction buffer from the PicoPure kit (Arcturus, Sunnyvale, CA, U.S.A.) were added. Samples were incubated at $42^{\circ} \mathrm{C}$ for $30 \mathrm{~min}$, centrifuged at $800 \mathrm{~g}$ for $2 \mathrm{~min}$, and stored at $-80^{\circ} \mathrm{C}$ until RNA isolation. 


\section{RNA isolation}

Total RNA was extracted from whole roots at different times after inoculation with G. intraradices spores, as well as from mock-inoculated roots, using the TRIZOL ${ }^{\circledR}$ Reagent (Invitrogen, Carlsbad, CA, USA). For each time point, roots from at least 12 individual plants were collected. Three independent experiments were carried out. The first cDNA was synthesized from DNase-treated total RNA $(1 \mu \mathrm{g})$ with M-MLV (Moloney-Murine Leukemia Virus) Reverse Transcriptase (Invitrogen, Carlsbad, CA, USA). Aliquots of the resulting RT reaction product were used as template for PCR analysis.

RNA isolations from laser microdissected cells were performed using a modified PicoPure kit protocol (Arcturus, Sunnyvale, CA, USA). Essentially, the DNasetreatment was not performed on the kit column but the RNA was eluted in $25 \mu \mathrm{l}$ of DEPC-treated $\mathrm{H}_{2} \mathrm{O}$ and then treated with RNAse-free DNase (Roche, Mannhein, Germany). After precipitation with 0.1 vol. of $3 \mathrm{M} \mathrm{Na}$ acetate and 2.5 vol. cold ethanol (100\%), the RNA was resuspended in $20 \mu \mathrm{l}$ of sterile water and quantified using the NanoDrop 1000 spectrophotometer.

\section{Gene expression analysis}

Quantitative real time PCR (RT-qPCR) analyses were carried out in optical 96-well plates in a LightCycler ${ }^{\circledR}$ 480 Real-Time PCR System (Roche) according to the following program: $10 \mathrm{~min}$ at $95^{\circ} \mathrm{C}$, followed by 45 cycles of $95^{\circ} \mathrm{C}$ for $10 \mathrm{~s}, 60^{\circ} \mathrm{C}$ for $30 \mathrm{~s}$, and an additional cycle of dissociation curves to ensure an unique amplification. The reaction mixture contained $10 \mu \mathrm{l} 2 \times$ SYBR Green Master mix reagent (Roche, Mannhein, Germany), $2 \mu \mathrm{l}$ cDNA sample, and $300 \mu \mathrm{M}$ of each gene-specific primers, in a final volume of $20 \mu \mathrm{l}$. Primers used for RT-qPCR are indicated in Additional file 6: Table S3. Details on RT-qPCR analysis following the MIQE guidelines [55] are included in Additional file 7. Routinely, three replicate reactions were used for each sample. Data were normalized with OsAct1 as internal control. The average CT values from triplicate PCRs were normalized to the average CT values for the OsAct1 gene from the same RNA preparations. Three independent biological replicates were analyzed. For each biological material, three technical replicates were made for RT-qPCR analysis.

In this work, semi-quantitative reverse-transcriptionpolymerase chain reaction (RT-PCR) was carried out to investigate the expression pattern of the rice $C P K$ genes, as well as the rice $S Y M$ genes, namely the OSSYMRK, OsCCaMK, OsPOLLUX and OsCASTOR genes. (Additional file 8: Table S4 and Additional file 9: Supplementary Methods).

For RT-PCR analysis of RNA samples obtained from laser microdissected cells, a one-step RT-PCR was conducted according to the manufacturer's instructions (Qiagen GmbH, Hilden, Germany). A $20 \mu \mathrm{l}$ reaction was prepared, containing the following reagents for each reaction: $4 \mu \mathrm{l}$ of (5X) Qiagen one-step RT-PCR buffer, 0,5 $\mu \mathrm{l}$ of Qiagen one-step RT-PCR enzyme mix, 0,5 mM of each dNTP, $0,25 \mu \mathrm{M}$ of each primer, $21 \mathrm{ng}$ of total RNA and RNase free water to $20 \mu l$.

\section{Phylogenetic analysis}

The full length protein sequences were obtained from the NCBI database and aligned using ClustalW [56]. The alignment of the various plant CPKs was created with GeneDoc 2.7.0 Software [57] and is shown in Additional File 4.

In addition to the $31 \mathrm{CPKs}$ from rice, known full-length CPK sequences from M. truncatula, M. sativa and Zea mays were also used. They were (accession numbers are from Gene Bank at the National Center for Biotechnology Information (NCBI) database http://www.ncbi.nlm.nih. gov/: MtCDPK1 [AAX15706], MtCDPK3 [ABE72958], and MsCDPK3, X96723]; ZmCDPK1 [BAA12338], $\mathrm{ZmCDPK2}$ [AAA69507], ZmCDPK7 [BAA13232], ZmCDPK9 [BAA12715], ZmCDPK10 [CAA07481] and ZmCDPK11 [AAP57564]. As for wheat, up to 20 CPKs have been described from which 14 available sequences were included in this study [45]. They were: TaCPK1 [ABY59004], ТаCPK2 [ABY59005], ТаСРК3 [ABY59006], TaCPK4 [ABY59007], TaCPK5 [ABY59008], TaCPK6 [ABY59009], TaCPK7 [ABY59017], TaCPK8 [ABY59010], TaCPK9 [ABY59011], TaCPK12 [ABY59012], TaCPK13 [ABY59018], TaCPK15 [ABY59013], TaCPK18 [ABY59014], TaCPK19 [ABY59015]. Furthermore, CCaMK sequences from rice, wheat and Medicago were included in this analysis, the rice OsCCaMK [Q6AVM3], wheat TaCCaMK [ADK22086] and M. truncatula MtCCaMK [Q6RET7] sequences. Phylogenetic trees were created according to the neighbor-joining method (Figure 4) or the maximum-parsimony algorithm (Additional File 3: Figure S3) using MEGA4 program [58,59].

\section{Promoter analysis}

Sequences 2000 bp upstream of the selected $c p k$ 's genes were retrieved from NCBI database. Known plant motifs were obtained from the PLACE database http://www. dna.affrc.go.jp/PLACE/.

\section{Biolistic cell transformation and imaging by confocal microscopy}

To investigate the subcellular localization of OsCPK18, the green fluorescent protein (GFP) gene was translationally fused to the C-terminal end of the OsCPK18 sequence. For this, a GFP gene lacking the N-terminal signal peptide and C-terminal HDEL sequences was initially obtained by PCR from the $m$-GFP5-ER sequence 
[60]. Primers used were 5'-CGGGGATCCATGAGTAAAGGAGAAGAACTTTTCAC-3' (forward) and 5'CCGAGCTCTTATTATTTGTATAGTTCATCCATGC3' (reverse). During the PCR reaction, BamHI and SacI sites were introduced into the PCR amplified DNA fragment (underlined nucleotides in PCR primer sequences). Next, the GFP variant was cloned between the BamHI and $S a c I$ sites of a pUC19-derived plasmid harboring the $35 \mathrm{SCaMV}$ promoter and nopaline synthetase terminator (Tnos) to create the PP35S:mGFP:nos construct.

The OsCPK18 DNA fragment to be translationally fused to the GFP gene was generated by PCR amplification. A BglII site was introduced at the 3'end of the PCR-amplified Oscpk18 DNA fragment. Equally, a SpeI site was introduced at the $5^{\prime}$ end of the Oscpk18 sequence. The full-length OsCPK18 cDNA sequence was PCR-amplified from clone J023148F12 obtained from the KOME (Knowledge-based Oryza Molecular biological Encyclopedia) database using the following primers: 5'-ATACTAGTATGGGACTCTGCTCCTCCTCC-3' (forward) and 5 - ATAGATCTACCTGGTGGTGGCGATCTGTGAACACTCCT-3' (reverse) (underlined sequences indicate the SpeI and BglII restriction sites; bold fonts indicate the residual tail of one glycine and three prolines to ensure the fusion). To obtain the chimeric OsCPK18-GFP gene, the PCR-amplified OsCPK18 DNA fragment was digested with SpeI and BglII and cloned into the $\mathrm{XbaI} / \mathrm{BamHI}$-digested pP35S:GFP:nos plasmid resulting in plasmid pP35S:OsCPK18-GFP:nos.

A chimeric gene in which a mutated version of OsCPK18 gene was fused to the GFP gene was also prepared. For preparation of the mutated version of the OsCPK18 gene in which the Gly residue at position 2 was converted to Ala (G2A), the pP35S:OsCPK18-GFP: nos plasmid was used as the template for PCR. For this, a forward primer with a single change (bold font) 5'ATACTAGTATGGCACTCTGCTCCTCCTCC-3', and the $O s C P K 18$ reverse primer above indicated were used. The OsCPK18 ${ }_{G 2 A}$ DNA was then cloned into the XbaI/ BamHI-digested pP35S:mGFP:nos plasmid. All the constructs were verified by nucleotide sequencing.

Onion epidermal cells were transformed by particle bombardment. The epidermis of onion bulb scales was prepared by peeling the inner epidermis from fresh onion bulbs. For each DNA construct, $4 \mu \mathrm{g}$ of DNA was mixed with $20 \mu \mu \mathrm{l}$ of $0.1 \mathrm{M}$ spermidine, $50 \mu \mu \mathrm{l}$ of $2.5 \mathrm{M} \mathrm{CaCl}_{2}$ and $15 \mu \mathrm{l}$ of gold microcarrier $\left(60 \mu \mathrm{g} \mathrm{ml}^{-}\right.$ ${ }^{1}$ in $50 \%$ glicerol), vortexed vigorously for $30 \mathrm{sec}$ and centrifuged at $800 \mathrm{~g}$ in a microfuge for $10 \mathrm{sec}$. The pellet was washed on ethanol. The DNA-gold particles were bombarded into cells at a pressure of $1100 \mathrm{psi}$ and target distance of $6 \mathrm{~cm}$, with a biolistic PSD$1000 /$ He particle delivery system (Bio-Rad). The transfected cells were kept on MS medium for 16-24 h in the dark. The subcellular localization of the fusion proteins was determined by confocal laser scanning microscopy (CLSM) in a Olympus Fluoview FV1000 confocal laser scanning microscope (Tokyo, Japan). The excitation wavelength was $488 \mathrm{~nm}$. The emission window was set at 500-600 nm for GFP. To confirm plasma membrane localization, cells were plasmolysed with $0.75 \mathrm{M}$ mannitol.

\section{Additional material}

Additional file 1: Figure S1: RT-PCR analysis of rice $C P K$ genes in mock-inoculated (-) and $G$. intraradices-inoculated (+) rice roots. Inoculation with $G$. intraradices spores was carried out using the singlesandwich system. Roots were harvested at different times after inoculation and each RNA sample was prepared from a pool of roots from 12 plants. RT-PCR was performed using specific primers for the indicated CPK genes. The subset of genes selected for expression analysis included members of the four phylogenetic groups of CPK genes (I-IV) (for details see Figure 4). Expression of rice SYM marker genes, the OsCCAMK, OsCASTOR, OsPOLLUX and OsSYMRK genes was analyzed in the same RNA samples that were used for analysis of CPK gene expression. Transcripts for the OsCPK2, OsCPK22, OsCPK25 and OsCPK31 could not be detected (results not shown, similar results were reported previously [40] by microarray analysis). The constitutively expressed actin1 (OsAct1) gene was used as the internal control in these experiments. Three independent experiments were carried out with similar results.

Additional file 2: Figure S2: Expression of the OsCPK4 gene in laser microdissected cells from rice roots. Cells were harvested from $G$. intraradices-inoculated (+Gi) and mock-inoculated (-Gi) roots. Total RNA samples were obtained from pooled microdissected cells. Expression analysis was carried out using the one-step procedure for RT and PCR amplification. Although different expression levels were observed in epidermal and cortical cells, RT-PCR analyses from RNA samples obtained from laser microdissected cells does not provide quantitative information on gene expression.

Additional file 3: Figure S3: Relationship between plant CPKs. The phylogenetic tree was constructed using the maximum parsimony method using the full length amino acid sequences of CPKs from rice (Os), wheat (Ta), maize ( $\mathrm{Zm}$ ) and Medicago (M. truncatula, Mt; M. sativa, Ms) and CCaMKs. The four groups are indicated (I-IV).

Additional file 4: Alignment of the amino acid sequences of plant CPKs and CCaMKs. Amino acid sequences from rice (Os), wheat (Ta), maize ( $Z \mathrm{~m})$ and Medicago (M. truncatula, Mt; M. sativa, Ms) were aligned. Black and gray backgrounds indicate amino acids that are identical or similar, respectively. Dashes indicate no residue present at that position. The boundaries of the kinase (amino acids 51-317 in OsCPK18) and calmoldulin-like (amino acids 347-493 in OsCPK18) domains are shown (black and grey arrows, respectively).

Additional file 5: Table S1 and Table S2. Table S1. Symbiosis-related cis-elements identified in the OsCPK18, OsCPK4, MtCPK1, OsCCAMK and MtCC $A M K$ promoters. The $2 \mathrm{~kb}$ upstream region of each promoter was analyzed by using the PLACE motif database. Table S2. Number of symbiosis-related cis-elements present in the OsCPK18, OsCPK4, MtCPK1, OsCCaMK and MtCCaMK promoters. The presence $(x)$ or absence $(-)$ of the indicated motifs within the $2 \mathrm{~kb}$ upstream region of each promoter is shown. Multiple copies of a given cis-element were present in a particular promoter $(2 x, 3 x, 4 x$, etc.). The PLACE motif database was used to perform this analysis. Motifs are listed by alphabetical order.

Additional file 6: Table S3: Primer sequences used in the real-time qPCR analysis.

Additional file 7: Information of the RT-qPCR analysis based on the MIQE (Minimum Information for Publication of Quantitative RealTime PCR Experiments) checklist [55]. 
Additional file 8: Table S4: Primer sequences used in the RT-PCR analysis.

Additional file 9: Supplementary Methods. Gene expression analysis by semi-quantitative RT-PCR.

\section{Acknowledgements}

LCS was a recipient of a predoctoral fellowship from the Generalitat de Catalunya. This work was supported by the "Acción Integrada" HI2007-0258 and grant BIO2009-08719 from the Spanish Ministry of Science and Innovation, as well as by the Consolider-Ingenio 2010 Programme CSD200700036 "Centre for Research in Agrigenomics". We also thank the "Departament d'Innovació, Universitats i Empresa" from the Generalitat de Catalunya (Xarxa de Referencia en Biotecnología and SGR 09626) for substantial support.

\section{Author details}

${ }^{1}$ Centre for Research in Agricultural Genomics (CRAG) CSIC-IRTA-UAB. Department of Molecular Genetics. Campus UAB, Edifici CRAG, Bellaterra (Cerdanyola del Vallès) 08193 Barcelona, Spain. ${ }^{2}$ Department of Plant Biology, University of Torino and Istituto per la Protezione delle Piante - CNR. Sezione di Torino. Viale P.A. Mattioli 25, Torino 10125, Italy.

\section{Authors' contributions}

LCS carried out most of the experimental work and data analyses. JGA participated in laser microdissection and gene expression studies. BSS coordinated the design and execution of this study and wrote the manuscript. PB also participated in the design of this study and critically revised the manuscript for important intellectual content. All authors read and approved the final manuscript.

Received: 18 February 2011 Accepted: 19 May 2011

Published: 19 May 2011

\section{References}

1. Smith S, Read D: Mycorrhizal Symbiosis London: Academic Press; 2008.

2. Parniske M: Arbuscular mycorrhiza: the mother of plant root endosymbioses. Nat Rev Micro 2008, 6:763-775.

3. Liu J, Maldonado-Mendoza I, Lopez-Meyer M, Cheung F, Town CD, Harrison MJ: Arbuscular mycorrhizal symbiosis is accompanied by local and systemic alterations in gene expression and an increase in disease resistance in the shoots. Plant J 2007, 50:529-544.

4. Campos-Soriano L, García-Garrido JM, SanSegundo B: Activation of basal defense mechanisms of rice plants by Glomus intraradices does not affect the arbuscular mycorrhizal symbiosis. New Phytol 2010, 188:597-614.

5. Sawers RJH, Gutjahr C, Paszkowski U: Cereal mycorrhiza: an ancient symbiosis in modern agriculture. Trends Plant Sci 2008, 13:93-97.

6. Akiyama K, Matsuzaki Ki, Hayashi H: Plant sesquiterpenes induce hyphal branching in arbuscular mycorrhizal fungi. Nature 2005, 435:824-827.

7. Maillet F, Poinsot V, Andre O, Puech-Pages V, Haouy A, Gueunier M, Cromer L, Giraudet D, Formey D, Niebel A, Martinez EA, Driguez H, Becard G, Denarie J: Fungal lipochitooligosaccharide symbiotic signals in arbuscular mycorrhiza. Nature 2011, 469:58-63.

8. Genre A, Chabaud M, Timmers T, Bonfante P, Barker DG: Arbuscular Mycorrhizal Fungi Elicit a Novel Intracellular Apparatus in Medicago truncatula Root Epidermal Cells before Infection. Plant Cell 2005, 17:3489-3499.

9. Chabaud M, Genre A, Sieberer BJ, Faccio A, Fournier J, Novero M, Barker DG, Bonfante P: Arbuscular mycorrhizal hyphopodia and germinated spore exudates trigger $\mathrm{Ca} 2+$ spiking in the legume and nonlegume root epidermis. New Phytol 2010, 347-355.

10. Kosuta S, Hazledine S, Sun J, Miwa H, Morris RJ, Downie JA, Oldroyd GED: Differential and chaotic calcium signatures in the symbiosis signaling pathway of legumes. Proc Natl Acad Sci USA 2008, 105:9823-9828.

11. Navazio L, Moscatiello R, Genre A, Novero M, Baldan B, Bonfante P, Mariani P: A Diffusible Signal from Arbuscular Mycorrhizal Fungi Elicits a Transient Cytosolic Calcium Elevation in Host Plant Cells. Plant Physiol 2007, 144:673-681.
12. Oldroyd GE, Downie JA: Nuclear calcium changes at the core of symbiosis signaling. Curr Opin Plant Biol 2006, 9:351-357.

13. Bonfante $P$, Genre A: Mechanisms underlying beneficial plant-fungus interactions in mycorrhizal symbiosis. Nat Commun 2010, 1:48.

14. Paszkowski U: A journey through signaling in arbuscular mycorrhizal symbioses. New Phytol 2006, 172:35-46.

15. Harrison MJ: Signaling in the arbuscular mycorrhizal symbiosis. Annu Rev Microbiol 2005, 59:19-42.

16. Charpentier M, Bredemeier R, Wanner G, Takeda N, Schleiff E, Parniske M: Lotus japonicus CASTOR and POLLUX Are Ion Channels Essential for Perinuclear Calcium Spiking in Legume Root Endosymbiosis. Plant Cell 2008, 20:3467-3479.

17. Kanamori N, Madsen LH, Radutoiu S, Frantescu M, Quistgaard EMH, Miwa H, Downie JA, James EK, Felle HH, Haaning LL, Jensen TH, Sato S, Nakamura Y, Tabata S, Sandal N, Stougaard J: A nucleoporin is required for induction of $\mathrm{Ca} 2+$ spiking in legume nodule development and essential for rhizobial and fungal symbiosis. Proc Natl Acad Sci USA 2006, 103:359-364.

18. Levy J, Bres C, Geurts R, Chalhoub B, Kulikova O, Duc G, Journet EP, Ane JM, Lauber E, Bisseling T, Denarie J, Rosenberg C, Debelle F: A Putative Ca2+ and Calmodulin-Dependent Protein Kinase Required for Bacterial and Fungal Symbioses. Science 2004, 303:1361-1364.

19. Saito K, Yoshikawa M, Yano K, Miwa H, Uchida H, Asamizu E, Sato S, Tabata S, Imaizumi-Anraku H, Umehara Y, Kouchi H, Murooka Y, Szczyglowski K, Downie JA, Parniske M, Hayashi M, Kawaguchi M: NUCLEOPORIN85 Is Required for Calcium Spiking, Fungal and Bacterial Symbioses, and Seed Production in Lotus japonicus. Plant Cell 2007, 19:610-624.

20. Stracke S, Kistner C, Yoshida S, Mulder L, Sato S, Kaneko T, Tabata S, Sandal N, Stougaard J, Szczyglowski K, Parniske M: A plant receptor-like kinase required for both bacterial and fungal symbiosis. Nature 2002, 417:959-962.

21. Yano K, Yoshida S, Müller J, Singh S, Banba M, Vickers K, Markmann K, White C, Schuller B, Sato S, Asamizu E, Tabata S, Murooka Y, Perry J, Wang TL, Kawaguchi M, Imaizumi-Anraku H, Hayashi M, Parniske M: CYCLOPS, a mediator of symbiotic intracellular accommodation. Proc Natl Acad Sci USA 2008, 105:20540-20545.

22. Messinese $E$, Mun JH, Yeun LH, Jayaraman D, Rougé P, Barre A, Lougnon G, Schornack S, Bono JJ, Cook DR, Ané JM: A Novel Nuclear Protein Interacts With the Symbiotic DMI3 Calcium- and Calmodulin-Dependent Protein Kinase of Medicago truncatula. Mol Plant Microbe Interact 2007, 20:912-921.

23. Chen C, Gao M, Liu J, Zhu H: Fungal Symbiosis in Rice Requires an Ortholog of a Legume Common Symbiosis Gene Encoding a Ca2 +/Calmodulin-Dependent Protein Kinase. Plant Physiol 2007, 145:1619-1628.

24. Godfroy O, Debelle F, Timmers T, Rosenberg C: A Rice Calcium- and Calmodulin-Dependent Protein Kinase Restores Nodulation to a Legume Mutant. Mol Plant Microbe Interact 2006, 19:495-501.

25. Gutjahr C, Banba M, Croset V, An K, Miyao A, An G, Hirochika H, ImaizumiAnraku H, Paszkowski U: Arbuscular Mycorrhiza-Specific Signaling in Rice Transcends the Common Symbiosis Signaling Pathway. Plant Cell 2008, 20:2989-3005.

26. Kuhn $\mathrm{H}$, Küster $\mathrm{H}$, Requena $\mathrm{N}$ : Membrane steroid-binding protein 1 induced by a diffusible fungal signal is critical for mycorrhization in Medicago truncatula. New Phytol 2010, 185:716-733.

27. Fiorilli V, Catoni M, Miozzi L, Novero M, Accotto GP, Lanfranco L: Global and cell-type gene expression profiles in tomato plants colonized by an arbuscular mycorrhizal fungus. New Phytol 2009, 184:975-987.

28. Gomez SK, Javot H, Deewatthanawong P, Torres-Jerez I, Tang Y, Blancaflor E, Udvardi M, Harrison M: Medicago truncatula and Glomus intraradices gene expression in cortical cells harboring arbuscules in the arbuscular mycorrhizal symbiosis. BMC Plant Biol 2009, 9:10.

29. Guether M, Balestrini R, Hannah M, He J, Udvardi MK, Bonfante P: Genomewide reprogramming of regulatory networks, transport, cell wall and membrane biogenesis during arbuscular mycorrhizal symbiosis in Lotus japonicus. New Phytol 2009, 182:200-212.

30. Güimil S, Chang HS, Zhu T, Sesma A, Osbourn A, Roux C, loannidis V, Oakeley EJ, Docquier M, Descombes P, Briggs SP, Paszkowski U: Comparative transcriptomics of rice reveals an ancient pattern of response to microbial colonization. Proc Natl Acad Sci USA 2005, 102:8066-8070. 
31. Balestrini R, Lanfranco L: Fungal and plant gene expression in arbuscular mycorrhizal symbiosis. Mycorrhiza 2006, 16:509-524.

32. Harrison MJ, Buuren ML: A phosphate transporter from the mycorrhizal fungus Glomus versiforme. Nature 1995, 378:626-629.

33. Klimecka M, Muszynska G: Structure and functions of plant calciumdependent protein kinases. Acta Biochim Pol 2007, 54:219-233.

34. Harper JF, Breton G, Harmon A: Decoding ca2+ signals through plant protein kinases. Annu Rev Plant Biol 2004, 55:263-288.

35. Cheng SH, Willmann MR, Chen HC, Sheen J: Calcium Signaling through Protein Kinases. The Arabidopsis Calcium-Dependent Protein Kinase Gene Family. Plant Physiol 2002, 129:469-485.

36. Harmon AC, Gribskov M, Gubrium E, Harper JF: The CDPK Superfamily of Protein Kinases. New Phytol 2001, 151:175-183.

37. Coca M, San Segundo B: AtCPK1 calcium-dependent protein kinase mediates pathogen resistance in Arabidopsis. Plant J 2010, 63:526-540

38. Romeis T, Piedras P, Jones JDG: Resistance Gene-Dependent Activation of a Calcium-Dependent Protein Kinase in the Plant Defense Response. Plant Cell 2000, 12:803-816.

39. Asano T, Tanaka N, Yang G, Hayashi N, Komatsu S: Genome-wide Identification of the Rice Calcium-dependent Protein Kinase and its Closely Related Kinase Gene Families: Comprehensive Analysis of the CDPKs Gene Family in Rice. Plant Cell Physiol 2005, 46:356-366.

40. Ray S, Agarwal P, Arora R, Kapoor S, Tyagi A: Expression analysis of calcium-dependent protein kinase gene family during reproductive development and abiotic stress conditions in rice Oryza sativa; L. ssp. indica. Mol Genet Genomics 2007, 278:493-505.

41. Weidmann S, Sanchez L, Descombin J, Chatagnier O, Gianinazzi S, Gianinazzi-Pearson V: Fungal Elicitation of Signal Transduction-Related Plant Genes Precedes Mycorrhiza Establishment and Requires the dmi3 Gene in Medicago truncatula. Mol Plant Microbe Interact 2004, 17:1385-1393.

42. Gutjahr C, Novero M, Guether M, Montanari O, Udvardi M, Bonfante P. Presymbiotic factors released by the arbuscular mycorrhizal fungus Gigaspora margarita induce starch accumulation in Lotus japonicus roots. New Phytol 2009, 183:53-61.

43. Balestrini R, Gómez-Ariza J, Lanfranco L, Bonfante P: Laser Microdissection Reveals That Transcripts for Five Plant and One Fungal Phosphate Transporter Genes Are Contemporaneously Present in Arbusculated Cells. Mol Plant Microbe Interact 2007, 20:1055-1062.

44. Gómez-Ariza J, Balestrini R, Novero M, Bonfante P: Cell-specific gene expression of phosphate transporters in mycorrhizal tomato roots. Biol Fert Soils 2009, 45:845-853.

45. Li AL, Zhu YF, Tan XM, Wang X, Wei B, Guo HZ, Zhang ZL, Chen XB, Zhao GY, Kong XY, Jia JZ, Mao L: Evolutionary and functional study of the CDPK gene family in wheat Triticum aestivum. Plant Mol Biol 2008, 66:429-443.

46. Higo K, Ugawa $\mathrm{Y}$, Iwamoto $\mathrm{M}$, Korenaga T: Plant cis-acting regulatory DNA elements (PLACE) database: 1999. Nucleic Acids Res 1999, 27:297-300

47. Stougaard J, Sandal NN, Grøn A, Kühle A, Marcker JA: $5^{\prime}$ Analysis of the soybean leghaemoglobin $\mathrm{Ibc}_{3}$ gene: regulatory elements required for promoter activity and organ specificity. EMBO J 1987, 6:3565-3569

48. Kaplan B, Davydov O, Knight H, Galon Y, Knight MR, Fluhr R, Fromm H: Rapid Transcriptome Changes Induced by Cytosolic Ca2+ Transients Reveal ABRE-Related Sequences as Ca2+-Responsive cis Elements in Arabidopsis. Plant Cell 2006, 18:2733-2748.

49. Yang T, Poovaiah BW: A Calmodulin-binding/CGCG Box DNA-binding Protein Family Involved in Multiple Signaling Pathways in Plants. J Biol Chem 2002, 277:45049-45058.

50. Rubio V, Linhares F, Solano R, Martín AC, Iglesias J, Leyva A, Paz-Ares J: A conserved MYB transcription factor involved in phosphate starvation signaling both in vascular plants and in unicellular algae. Genes Dev 2001, 15:2122-2133.

51. Wernimont AK, Artz JD, Finerty P, Lin YH, Amani M, lali-Hassani A, Senisterra G, Vedadi M, Tempel W, Mackenzie F, Chau I, Lourido S, Sibley LD, Hui R: Structures of apicomplexan calcium-dependent protein kinases reveal mechanism of activation by calcium. Nat Struct Mol Biol 2010, 17:596-601.

52. Wang B, Yeun LH, Xue JY, Liu Y, Ané JM, Qiu YL: Presence of three mycorrhizal genes in the common ancestor of land plants suggests a key role of mycorrhizas in the colonization of land by plants. New Phytol 2010, 186:514-525

53. Ivashuta S, Liu J, Liu J, Lohar DP, Haridas S, Bucciarelli B, VandenBosch KA, Vance CP, Harrison MJ, Gantt JS: RNA Interference Identifies a CalciumDependent Protein Kinase Involved in Medicago truncatula Root Development. Plant Cell 2005, 2911-2921.

54. Karas B, Amyot L, Johansen C, Sato S, Tabata S, Kawaguchi M Szczyglowski K: Conservation of Lotus and Arabidopsis Basic Helix-LoopHelix Proteins Reveals New Players in Root Hair Development. Plant Physiol 2009, 151:1175-1185.

55. Bustin SA, Benes V, Garson JA, Hellemans J, Huggett J, Kubista M, Mueller R, Nolan T, Pfaffl MW, Shipley GL, Vandesompele J, Wittwer CT: The MIQE Guidelines: Minimum Information for Publication of Quantitative RealTime PCR Experiments. Clin Chem 2009, 55:611-622.

56. Thompson JD, Higgins DG, Gibson TJ: CLUSTAL W: improving the sensitivity of progressive multiple sequence alignment through sequence weighting, position-specific gap penalties and weight matrix choice. Nucleic Acids Res 1994, 22:4673-4680.

57. Nicholas K, Nicholas H, Deerfield D: GeneDoc: analysis and visualization of genetic variation. EMBNEW NEWS 1997, 4:14.

58. Saitou N, Nei M: The neighbor-joining method: a new method for reconstructing phylogenetic trees. Mol Biol Evol 1987, 4:406-425.

59. Tamura K, Dudley J, Nei M, Kumar S: MEGA4: Molecular Evolutionary Genetics Analysis (MEGA) Software Version 4.0. Mol Biol Evol 2007, 24:1596-1599

60. Siemering KR, Golbik R, Sever R, Haseloff J: Mutations that suppress the thermosensitivity of green fluorescent protein. Curr Biol 1996, 6:1653-1663

doi:10.1186/1471-2229-11-90

Cite this article as: Campos-Soriano et al:: A rice calcium-dependent protein kinase is expressed in cortical root cells during the presymbiotic phase of the arbuscular mycorrhizal symbiosis. BMC Plant Biology 2011 11:90.

\section{Submit your next manuscript to BioMed Central and take full advantage of:}

- Convenient online submission

- Thorough peer review

- No space constraints or color figure charges

- Immediate publication on acceptance

- Inclusion in PubMed, CAS, Scopus and Google Scholar

- Research which is freely available for redistribution

Submit your manuscript at www.biomedcentral.com/submit
Ciomed Central 